\title{
Erratum to: Interplay between Swampland and Bayesian Machine Learning in constraining cosmological models
}

\author{
Emilio Elizalde $^{1,2, a}$, Martiros Khurshudyan ${ }^{1,2,3, b}$ (D) \\ ${ }^{1}$ Consejo Superior de Investigaciones Científicas, ICE/CSIC-IEEC, Campus UAB, Carrer de Can Magrans s/n, 08193 Bellaterra, Barcelona, Spain \\ ${ }^{2}$ International Laboratory for Theoretical Cosmology, Tomsk State University of Control Systems and Radioelectronics (TUSUR), 634050 Tomsk, \\ Russia \\ ${ }^{3}$ Institute of Physics, University of Silesia, Katowice, Poland
}

Published online: 21 May 2021

(C) The Author(s) 2021

\section{Erratum to: Eur. Phys. J. C (2021) 81:335 \\ https://doi.org/10.1140/epjc/s10052-021-09130-8}

In the original article, the first sentence of the conclusion section was cut.

The correct beginning reads as follows:

"We say nothing new when stating that Machine Learning,..."

The original article has been corrected.

Open Access This article is licensed under a Creative Commons Attribution 4.0 International License, which permits use, sharing, adaptation, distribution and reproduction in any medium or format, as long as you give appropriate credit to the original author(s) and the source, provide a link to the Creative Commons licence, and indicate if changes were made. The images or other third party material in this article are included in the article's Creative Commons licence, unless indicated otherwise in a credit line to the material. If material is not included in the article's Creative Commons licence and your intended use is not permitted by statutory regulation or exceeds the permitted use, you will need to obtain permission directly from the copyright holder. To view a copy of this licence, visit http://creativecomm ons.org/licenses/by/4.0/.

Funded by $\mathrm{SCOAP}^{3}$.

The original article can be found online at https://doi.org/10.1140/ epjc/s10052-021-09130-8.

a e-mail: elizalde@ieec.uab.es

b e-mail: khurshudyan@ice.csic.es (corresponding author) 